\title{
Routine cine-CMR segmentation via a novel automated algorithm (LV-METRIC) for assessment of aortic physiology: a clinical validation study
}

\author{
Parmanand Singh ${ }^{1 *}$, Noel C Codella², Yi Wang ${ }^{1}$, Zaid I Almarzooq', Nisha Bavalia', Grace Malonga', \\ Steven M Markowitz', Mary J Roman', Richard B Devereux', Jonathan W Weinsaft ${ }^{1}$
}

From 18th Annual SCMR Scientific Sessions

Nice, France. 4-7 February 2015

\section{Background}

Routine cine-CMR is widely used to assess cardiac structure and function. Partial voxel interpolation has been shown to yield improved agreement with phantom derived chamber volumes and necropsy evidenced LV mass; the utility of partial voxel interpolation for assessment of aortic physiology has never before been tested.

\section{Methods}

Cine-CMR (SSFP) was performed on 1.5 Tesla (GE) scanners; pulse sequence parameters were equivalent to those for routine CMR (typical TR $3.4 \mathrm{msec}$, TE 1.14 msec, flip angle $60^{\circ}$, temporal resolution $30 \mathrm{msec}$ ). Images were acquired in conventional cardiac (2, 3, 4 chamber) long axis or axial imaging planes. Aortic area was uniformly measured in a non-aneurysmal location within the mid-descending thoracic aorta: Cine-CMR was quantified via a novel "partial voxel" segmentation algorithm (LV-METRIC) that accounts for relative proportion of blood within each individual imaging voxel. Maximum (systolic) and minimum (diastolic) aortic areas and brachial pulse pressure were used to calculate distensibility, a measure of arterial compliance, of the mid-descending thoracic aorta.

\section{Results}

32 subjects were studied, among whom 22 had genetically-mediated aortopathies (13 bicuspid aortic valve [BAV], 9 Marfan syndrome [MFS]) and 10 were normative controls. Aortopathy subjects were similar to controls in age, gender, pulse pressure and body size (all $\mathrm{p}=\mathrm{NS}$ ). Aortic indices, compared between MFS, BAV and control groups are shown in Figure 1. As shown, absolute aortic size (measured in a non-aneurysmal region) was similar between groups (all $\mathrm{p}=\mathrm{NS}$ ). Dynamic change in aortic area ( $\Delta$ Area) was lesser among MFS

Table 1: Aortic Physiologic Indices as Assessed by Routine Cine-CMR

\begin{tabular}{|l|c|c|c|c|c|}
\hline & Controls & Bicuspid Aortic Valve & Marfan Syndrome & $\begin{array}{c}\text { p-value } \\
\text { (BAV vs. control) }\end{array}$ & $\begin{array}{c}\text { p-value } \\
\text { (Marfan vs. control) }\end{array}$ \\
\hline Area (mean) & $3.12 \pm 0.44$ & $3.04 \pm 0.67$ & $3.42 \pm 2.13$ & 0.47 & 0.67 \\
\hline Maximal Area (systole) & $3.51 \pm 0.48$ & $3.39 \pm 0.48$ & $3.69 \pm 2.08$ & 0.68 & 0.81 \\
\hline Minimal Area (diastole) & $2.77 \pm 0.35$ & $2.65 \pm 0.66$ & $3.20 \pm 2.04$ & 0.59 & 0.55 \\
\hline$\Delta$ Area & $0.74 \pm 0.18$ & $0.74 \pm 0.30$ & $0.48 \pm 0.15$ & 0.99 & $\mathbf{0 . 0 0 4}$ \\
\hline Distensibility & $6.96 \pm 0.38$ & $6.31 \pm 2.83$ & $4.31 \pm 1.96$ & 0.43 & $\mathbf{0 . 0 0 7}$ \\
\hline
\end{tabular}

Figure 1 Aortic physiologic indices as assessd by routine cine-CMR

${ }^{1}$ Medicine- Cardiology, Weill Cornell Medical College, New York, NY, USA

Full list of author information is available at the end of the article 
vs. controls $(\mathrm{p}=0.004)$ as well as BAV $(\mathrm{p}=0.03)$, but not between BAV vs controls $(\mathrm{p}=0.99)$. Aortic distensibility, as measured in all aortopathy subjects and 6 normative controls, demonstrated lower values among MFS subjects as compared to normative controls $(\mathrm{p}=0.007)$, with a similar trend when MFS and BAV groups were compared $(\mathrm{p}=0.08)$. There was no significant difference in distensibility between BAV vs controls $(\mathrm{p}=0.43)$.

\section{Conclusions}

Routine cine-CMR can discern altered aortic physiology in non-aneurysmal regions in subjects with MFS. Larger longitudinal studies are needed to further evaluate the prognostic utility of cine-CMR segmentation, including use of central aortic blood pressure, as a potential biomarker of early aortic disease.

\section{Funding}

Not applicable.

Authors' details

'Medicine- Cardiology, Weill Cornell Medical College, New York, NY, USA.

${ }^{2}$ IBM T.J. Watson Research Center, New York, NY, USA.

Published: 3 February 2015

doi:10.1186/1532-429X-17-S1-P387

Cite this article as: Singh et al: Routine cine-CMR segmentation via a novel automated algorithm (LV-METRIC) for assessment of aortic physiology: a clinical validation study. Journal of Cardiovascular Magnetic Resonance 2015 17(Suppl 1):P387.
Submit your next manuscript to BioMed Central and take full advantage of:

- Convenient online submission

- Thorough peer review

- No space constraints or color figure charges

- Immediate publication on acceptance

- Inclusion in PubMed, CAS, Scopus and Google Scholar

- Research which is freely available for redistribution

Submit your manuscript at www.biomedcentral.com/submit 